\title{
Crystal structures and gas adsorption behavior of new lanthanide-benzene-1,4-
}

dicarboxylate frameworks

Kitt Panyarat, ${ }^{\mathrm{a}, \mathrm{b}}$ Sireenart Surinwong, ${ }^{\mathrm{c}}$ Timothy J. Prior, ${ }^{\mathrm{d}}$ Takumi Konno, ${ }^{\mathrm{c}}$ Apinpus

Rujiwatra ${ }^{\mathrm{a}, *}$

aDepartment of Chemistry, Faculty of Science, Chiang Mai University, Chiang Mai 50200

Thailand

${ }^{\mathrm{b}}$ Graduate School, Chiang Mai University, Chiang Mai 50200, Thailand

${ }^{c}$ Department of Chemistry, Graduate School of Science, Osaka University, Toyonaka, Osaka 560-0043, Japan

${ }^{\mathrm{d}}$ Chemistry, The University of Hull, Cottingham Road, Hull HU6 7RX, UK

To whom correspondence should be addressed.

Department of Chemistry,

Faculty of Science,

Chiang Mai University,

Chiang Mai 50200 Thailand

Tel. +66 5394 1906, Fax. +66 53892277

E-mail: apinpus.rujiwatra@cmu.ac.th 


\title{
Crystal structures and gas adsorption behavior of new lanthanide-benzene-1,4- dicarboxylate frameworks
}

Kitt Panyarat, ${ }^{\mathrm{a}, \mathrm{b}}$ Sireenart Surinwong, ${ }^{\mathrm{c}}$ Timothy J. Prior, ${ }^{\mathrm{d}}$ Takumi Konno, ${ }^{\mathrm{c}}$ Apinpus

Rujiwatra ${ }^{\mathrm{a}, *}$

aDepartment of Chemistry, Faculty of Science, Chiang Mai University, Chiang Mai 50200

Thailand

${ }^{\mathrm{b}}$ Graduate School, Chiang Mai University, Chiang Mai 50200, Thailand

${ }^{c}$ Department of Chemistry, Graduate School of Science, Osaka University, Toyonaka, Osaka 560-0043, Japan

${ }^{\mathrm{d} C h e m i s t r y, ~ T h e ~ U n i v e r s i t y ~ o f ~ H u l l, ~ C o t t i n g h a m ~ R o a d, ~ H u l l ~ H U 6 ~ 7 R X, ~ U K ~}$

\begin{abstract}
Six new lanthanide metal organic complexes, i.e. $\left[\mathrm{La}_{2}\left(\mathrm{NO}_{2}-\mathrm{BDC}\right)_{3}\left(\mathrm{H}_{2} \mathrm{O}\right)_{4}\right]$ (1) $\left[\mathrm{Ln}(\mathrm{L})_{0.5}\left(\mathrm{NO}_{2}-\mathrm{BDC}\right)\left(\mathrm{H}_{2} \mathrm{O}\right)\right]^{3} 3 \mathrm{H}_{2} \mathrm{O}\left(\mathrm{Ln}=\mathrm{Eu}(\mathbf{2}), \mathrm{Tb}(\mathbf{3})\right.$, Dy (4) and Ho (5); $\mathrm{L}=\mathrm{BDC}^{2-}$ or $\left.\mathrm{BDC}^{2-} / \mathrm{NO}_{2}-\mathrm{BDC}^{2-}\right)$ and $\left[\mathrm{Tm}\left(\mathrm{NO}_{2}-\mathrm{BDC}\right)_{1.5}\left(\mathrm{H}_{2} \mathrm{O}\right)\right] \cdot \mathrm{H}_{2} \mathrm{O}(\mathbf{6})$, have been synthesized using mixed ligands of benzene-1,4-dicarboxylic acid $\left(\mathrm{H}_{2} \mathrm{BDC}\right)$ and the in situ generated 2-nitrobenzene-1,4-dicarboxylic acid $\left(\mathrm{NO}_{2}-\mathrm{BDC}^{2-}\right)$. Single crystal structures and topologies of the complexes are presented based on the single crystal X-ray diffraction and spectroscopic data. Whilst the structures of $\mathbf{1}$ and $\mathbf{6}$ contain negligible voids, the frameworks of 2-5 are microporous in nature and stable upon the removal of all the water molecules from the structures and thermal treatment to over $400{ }^{\circ} \mathrm{C}$. Based on the study of $\mathbf{2}$, significant adsorption capacities for carbon dioxide $\left(95 \mathrm{~cm}^{3} \cdot \mathrm{g}^{-1}\right.$ or $\left.4.2 \mathrm{mmol} \cdot \mathrm{g}^{-1}\right)$ and hydrogen $(79$ $\mathrm{cm}^{3} \cdot \mathrm{g}^{-1}$ or $\left.4 \mathrm{mmol} \cdot \mathrm{g}^{-1}\right)$, as well as the remarkable stability of the framework upon the sorption/desorption experiments are revealed.
\end{abstract}


Keywords: Metal organic framework; lanthanide; benzenedicarboxylate; gas adsorption; crystal structure

\section{Introduction}

Environmental impact caused by the emission of greenhouse gases has become a major global concern which therefore demands technologies to control the emission of such gases especially carbon dioxide which is reported to be the primary culprit for the rising of global temperature $[1,2]$. Despite extensive research on the capture of carbon dioxide in the last two decades, none of the existing technologies have fulfilled the target performance criteria; for example, large capture capacity, high selectivity, optimal affinity and high stability under capture and regeneration conditions [3-5]. Among the capturing techniques under investigation at the present, solid sorbent materials and metal organic frameworks (MOFs) draw an immense interest as the most promising candidates. This is due to their unprecedentedly high active surface area, remarkably large void volume, structural and chemical robustness, and potential to be tailor-made, up-scaled and made into membranes $[4,6-8]$. Since the first report of $[\mathrm{Zn}(\mathrm{BDC})] \cdot(\mathrm{DMF})\left(\mathrm{H}_{2} \mathrm{O}\right)(\mathrm{BDC}=$ benzene-1,4-dicarboxylate and $\mathrm{DMF}=\mathrm{N}, \mathrm{N}^{\prime}$-dimethylformamide) with promising carbon dioxide capture capacity [9], several series of new MOFs with encouraging performance have been reported. Strategies to enhance the capture capacities and selectivity such as the generation of unsaturated or open metal sites, the fabrication of flexible interpenetrating frameworks, and the installation of desired functionalities on the organic linkers have been proposed [4,10,11]. Regarding the open metal sites, lanthanide metal ions are deemed to be judicious choices as they tend to include small solvent molecules in their coordination sphere which can be removed to generate open metal sites without framework disruption. In addition, there is a tendency for lanthanide metal ions to provide robust frameworks of high dimensionality with adjustable 
pore characteristics. The study of lanthanide MOFs for carbon dioxide capture has thus far been limited with only few examples reported; $\mathrm{Tb}_{2}(\mathrm{BDC})_{3}[12], \mathrm{Tb}(\mathrm{BDC}) \mathrm{NO}_{3}[13]$ and $\left[\mathrm{Ln}_{2}(\mathrm{TPO})_{2}(\mathrm{HCOO})\right] \cdot\left(\mathrm{Me}_{2} \mathrm{NH}_{2}\right) \cdot(\mathrm{DMF})_{4} \cdot(\mathrm{H} 2 \mathrm{O})_{6}\left(\mathrm{Ln}=\mathrm{Y}\right.$ and $\mathrm{Eu}, \mathrm{H}_{3} \mathrm{TPO}=$ tris- $(4-$ carboxylphenyl)phosphineoxide, DMF $=\mathrm{N}, \mathrm{N}$-dimethylformamide) [14].

Here, a series of six new lanthanide MOFs have been designed and synthesized using $\mathrm{NO}_{2}-\mathrm{BDC}^{2-}$ and $\mathrm{BDC}^{2-}$ as the primary linkers because of its tendency to generate microporous frameworks which was reported to be suitable for carbon dioxide capture $[9,15]$. In situ nitration was employed to introduce the nitro group to $\mathrm{BDC}^{2-}$ and therefore to generate the multivariate frameworks comprising both $\mathrm{BDC}^{2-}$ and $\mathrm{NO}_{2}-\mathrm{BDC}^{2-}$ linkers. The inclusion of the nitro group was intended to increase the interaction of the framework and carbon dioxide [16]. Four of the six reported complexes are microporous with accessible voids, extraordinary stability and significant gas capture capacities. The photoluminescence properties of the complexes have also been investigated.

\section{Experimental}

\subsection{Materials and methods}

All chemicals were obtained commercially and used without further purification; $\mathrm{La}_{2} \mathrm{O}_{3}\left(99.9 \%\right.$, Merck), $\mathrm{Eu}_{2} \mathrm{O}_{3}$ (99.9\%, Merck), $\mathrm{Tb}_{2} \mathrm{O}_{3}$ (99.9\%, Merck), $\mathrm{Dy}_{2} \mathrm{O}_{3}(99.9 \%$, Fluka), $\mathrm{Ho}_{2} \mathrm{O}_{3}\left(99 \%\right.$, Prolabo), $\mathrm{Er}_{2} \mathrm{O}_{3}$ (99\%, Fluka), $\mathrm{Tm}_{2} \mathrm{O}_{3}$ (99\%, Merck), $\mathrm{HNO}_{3}(\geq 90 \%$, Sigma-Aldrich), benzene-1,4-dicarboxylic acid $\left(\mathrm{H}_{2} \mathrm{BDC}_{3} \mathrm{C}_{8} \mathrm{H}_{6} \mathrm{O}_{4}, 97 \%\right.$, BDH), and 1,4diazabicyclo[2.2.2] octane (DABCO; $\mathrm{C}_{6} \mathrm{H}_{12} \mathrm{~N}_{2}, 98 \%$, Sigma-Aldrich).

Infrared (IR) spectra were recorded using a Bruker Tensor 27 FT-IR instrument and $\mathrm{KBr}$ discs $(98.5 \%, \mathrm{BDH})$. Thermogravimetric analyses were conducted on a Perkin Elmer Pyris Diamond TG/DTA using a heating rate of $10^{\circ} \mathrm{C} \cdot \mathrm{min}^{-1}$ from room temperature to 1000 ${ }^{\circ} \mathrm{C}$ in a nitrogen gas flow. Powder X-ray diffraction (PXRD) experiments were conducted 
using a Bruker D8 Advance X-ray diffractometer operated with Ni filtered $\mathrm{Cu} K \alpha$ radiation $(\lambda=1.5418 \AA, 48 \mathrm{kV}, 30 \mathrm{~mA})$. The gas sorption experiments were performed using a BELSORP-mini II instrument in a range of 0-1 bar pressures. Ultra-pure research grade nitrogen, hydrogen and carbon dioxide gases were used. The samples were heated at $250{ }^{\circ} \mathrm{C}$ for $2 \mathrm{~h}$ under vacuum before the measurements which were performed at $77 \mathrm{~K}$ for the nitrogen and hydrogen and at $195 \mathrm{~K}$ for the carbon dioxide. Photoluminescence spectra were collected at room temperature using an Avantes Multichannel spectrometer with the Ocean Optics LED $255 \mathrm{~nm}$ excitation source.

\subsection{Hydrothermal syntheses of 1-6}

To synthesize $\left[\mathrm{La}_{2}\left(\mathrm{NO}_{2}-\mathrm{BDC}\right)_{3}\left(\mathrm{H}_{2} \mathrm{O}\right)_{4}\right](\mathbf{1})\left[\mathrm{Ln}(\mathrm{L})_{0.5}\left(\mathrm{NO}_{2}-\mathrm{BDC}\right)\left(\mathrm{H}_{2} \mathrm{O}\right)\right] 3 \mathrm{H}_{2} \mathrm{O}\{\mathrm{Ln}=$ $\mathrm{Eu}(\mathbf{2}), \mathrm{Tb}(3)$, Dy (4) and $\mathrm{Ho}(\mathbf{5}) ; \mathrm{L}=\mathrm{BDC}^{2-}$ or $\left.\mathrm{BDC}^{2-} / \mathrm{NO}_{2}-\mathrm{BDC}^{2-}\right\}$ and $\left[\mathrm{Tm}\left(\mathrm{NO}_{2-}\right.\right.$ BDC $\left.) 1.5\left(\mathrm{H}_{2} \mathrm{O}\right)\right] \cdot \mathrm{H}_{2} \mathrm{O}(6)$, the solution of the corresponding $\mathrm{Ln}_{2} \mathrm{O}_{3}$ was first prepared by dissolving the $\mathrm{Ln}_{2} \mathrm{O}_{3}(1.70 \mathrm{mmol})$ in $1.00 \mathrm{~mL}$ of concentrated $\mathrm{HNO}_{3}$ aqueous solution. Each solution was then mixed with $10.0 \mathrm{~mL}$ of an aqueous solution containing $\mathrm{H}_{2} \mathrm{BDC}$ (4.0 mmol) and DABCO (4.0 mmol) with vigorous stirring. The $\mathrm{Ln}_{2} \mathrm{O}_{3}: \mathrm{HNO}_{3}: \mathrm{H}_{2} \mathrm{BDC}: \mathrm{DABCO}: \mathrm{H}_{2} \mathrm{O}$ mole ratio of every reaction was $1.70: 5.16: 4.00: 4.00: 556$. The reactions were performed using a $23.0 \mathrm{~mL}$ Teflon lined hydrothermal autoclave under an autogenous pressure generated at $180{ }^{\circ} \mathrm{C}$ for $24 \mathrm{~h}$, and afforded a few crystals as the solid products.

\subsection{X-ray crystallography}

Diffraction data of $\mathbf{1}$ and $\mathbf{6}$ were collected on a Bruker APEX-II CCD diffractometer and a Stoe IPDS2 image plate diffractometer, respectively, whereas those of 2-5 were collected on a Bruker D8 QUEST CMOS diffractometer. The machines were operated using Mo $K \alpha$ radiation $(\lambda=0.71073 \AA)$ at $298(2) K$ for $\mathbf{1 - 5}$ and $150(2) K$ for $\mathbf{6}$. Data reduction and 
an adsorption correction of 1-5 were performed with the SAINT [17] and SADABS [18] software packages, whilst that of $\mathbf{6}$ was done using the Tompa method [19]. The structures were solved by direct methods implemented within SHELXS-86 [20] and full-matrix least squares refinements were carried out on $F^{2}$ for all data with the program SHELXL-97 [20] via either the WinGX [21] or the OLEX2 [22] program interfaces. Non-hydrogen atoms were refined anisotropically, and the hydrogen atoms on the organic ligands were located at ideal geometrical positions using a riding model. No hydrogen atoms were assigned on the unbound water molecules. Crystallographic and refinement data are summarized in Table 1.

\section{Results and discussion}

\subsection{Hydrothermal crystal growth and in situ ligand synthesis}

Following our interest in extending the use of lanthanide ions in fabricating new microporous frameworks [23], six new complexes have been synthesized. The colors of the crystals are in good agreement with the characteristic colors of the corresponding lanthanide ions. The crystals showed a tint of yellow color which is consistent with the presence of the nitrated $\mathrm{BDC}^{2-}\left(\mathrm{NO}_{2}-\mathrm{BDC}^{2-}\right)$ derived in situ under strong acidic hydrothermal conditions $[23,24]$. The existence of $\mathrm{NO}_{2}-\mathrm{BDC}^{2-}$ is confirmed by characteristic $v(\mathrm{C}-\mathrm{N})$ and $v(\mathrm{~N}-\mathrm{O})$ in the IR spectra of all complexes (see Appendix). To the best of our knowledge, these lanthanide MOFs can be regarded as one of the very few multivariate lanthanide MOFs yielded by using the in situ ligand synthesis strategy. It should be however noted that the formation of nitrosamines may be possible under the employed condition according to the previous literature reporting on the formation of these powerful carcinogens under similar synthesis condition [25].

The employment of the in situ nitration in the synthesis results nonetheless in pronounced disorder in the structures of the synthesized complexes. In the cases of $\mathbf{1}$ and $\mathbf{6}$ in 
which there are two $\mathrm{NO}_{2}-\mathrm{BDC}^{2-}$ in the asymmetric unit, the nitro group on one of the $\mathrm{NO}_{2}$ $\mathrm{BDC}^{2-}$ ligands in both structures shows disorder over two sites with approximately equal occupancies of $50 \%$. Similar site disorder is also observed in the structures of $\mathbf{3}$ and $\mathbf{5}$ which are isostructural to $\mathbf{2}$ and $\mathbf{4}$. The disorder in structures $\mathbf{2}$ and $\mathbf{4}$ is however more complicated and similar to those observed in $\left[\mathrm{Ln}\left(\mathrm{NO}_{2}-\mathrm{BDC}\right)(\mathrm{L})_{0.5}\left(\mathrm{H}_{2} \mathrm{O}\right)\right] \cdot 3 \mathrm{H}_{2} \mathrm{O}(\mathrm{Ln}=\mathrm{Pr}, \mathrm{Nd}, \mathrm{Sm}$ and $\mathrm{Gd}$, and $\mathrm{L}=\mathrm{BDC}^{2-}$ or $\mathrm{BDC}^{2-} / \mathrm{NO}_{2}-\mathrm{BDC}^{2-}$ ) [23]. In addition to site disorder at the nitro group of one of the $\mathrm{NO}_{2}-\mathrm{BDC}^{2-}$ ligands, there are two types of crystallographic disorder, including site and substitutional disorder, at the nitro group of the other ligand. This suggests the coexistence of both $\mathrm{BDC}^{2-}$ and $\mathrm{NO}_{2}-\mathrm{BDC}^{2-}$ of which the nitro group on the $\mathrm{NO}_{2}-\mathrm{BDC}^{2-}$ shows additional site disorder over two crystallographic sites with equal site occupancy. The BDC ${ }^{2-}$ to- $\mathrm{NO}_{2}-\mathrm{BDC}^{2-}$ ratios in both structures are intriguingly similar of approximately $0.7: 0.3$. Given the synthetic conditions the variable degree of nitration is not unexpected.

Despite the addition of DABCO in the reaction, the absence of DABCO in the title structures should be noted. The attempts to synthesize the title complexes without the addition of DABCO were however unsuccessful, suggesting the crucial role of this organic base in the synthesis. Acid-base reaction between $\mathrm{H}_{2} \mathrm{BDC}$ and $\mathrm{DABCO}$ can be assumed [26]. The deprotonation of the carboxyl groups of $\mathrm{H}_{2} \mathrm{BDC}$ by such acid-base reaction should generate free carboxylate groups on the organic ligands to coordinate lanthanide metal ions.

\subsection{Crystal structures of 1-6}

$\left[\mathrm{La}_{2}\left(\mathrm{NO}_{2}-\mathbf{B D C}\right)_{3}\left(\mathrm{H}_{2} \mathrm{O}\right)_{4}\right](\mathbf{1})$. Complex $\mathbf{1}$ crystallizes in the triclinic space group $P \overline{1}$ with two unique lanthanum ions in the asymmetric unit (Fig. 1a). The two distinct lanthanum ions are similarly eight-fold coordinated by eight oxygen atoms from the carboxylates of six $\mathrm{NO}_{2}-\mathrm{BDC}^{2-}$ and two coordinated water molecules, and form a distorted square-face bicapped trigonal prismatic unit, TPRS- $\left\{\mathrm{LaO}_{8}\right\}$, alike. All of the $\mathrm{NO}_{2}-\mathrm{BDC}^{2-}$ function as the 
tetradentate linkers using the $\mu_{4}-\eta^{1}: \eta^{1}: \eta^{1}: \eta^{1}$ coordination mode, leading to the formation of the three-dimensional $\left[\mathrm{La}_{2}\left(\mathrm{NO}_{2}-\mathrm{BDC}\right)_{3}\left(\mathrm{H}_{2} \mathrm{O}\right)_{4}\right]$ framework. The framework of $\mathbf{1}$ is a dense framework without any void according to calculations using PLATON [27], and can be viewed as being composed of two-dimensional puckered layers spreading in the ac plane which are further pillared by the organic ligands in the direction of $b$ (Fig. 1b). The framework can be simplified to the uninodal 6-connected pcu $\alpha$-Po net with $\left\{4^{12} \cdot 6^{3}\right\}$ point symbol using the TPRS- $\left\{\mathrm{LaO}_{8}\right\}$ units as nodes and the $\mathrm{NO}_{2}-\mathrm{BDC}^{2-}$ as linker (Fig. 1c). The framework of $\mathbf{1}$ is governed mainly by very strong $\mathrm{O}-\mathrm{H} \cdots \mathrm{O}$ hydrogen bonding interactions involving every coordinated water molecules and the nitro groups of $\mathrm{NO}_{2}-\mathrm{BDC}^{2-}$ (Table 2). The hydrogen bonding interactions are in good agreement with the apparent disorder in the structure of $\mathbf{1}$ and additionally result in an arrangement of the organic ligand that prohibits any $\pi-\pi$ interaction.

\section{$\left[\mathrm{Ln}(\mathrm{L})_{0.5}\left(\mathrm{NO}_{2}-\mathrm{BDC}\right)\left(\mathrm{H}_{2} \mathrm{O}\right)\right]^{3} 3 \mathrm{H}_{2} \mathrm{O}\{\mathrm{Ln}=\mathrm{Eu}(2), \mathrm{Tb}(3)$, Dy (4) and Ho (5); L =} $\mathbf{B D C}^{2-}$ or $\left.\mathbf{B D C}^{2-} / \mathrm{NO}_{2}-\mathbf{B D C}^{2-}\right\}$. Complexes $2-5$ are isostructural and crystallize in the same orthorhombic space group Pbca (Table 1). The unit cell parameters of 2-5 are in good agreement with those of $\left[\mathrm{Ln}\left(\mathrm{NO}_{2}-\mathrm{BDC}\right)(\mathrm{L})_{0.5}\left(\mathrm{H}_{2} \mathrm{O}\right)\right] \cdot 3 \mathrm{H}_{2} \mathrm{O}(\mathrm{Ln}=\mathrm{Pr}, \mathrm{Nd}$, Sm and $\mathrm{Gd} ; \mathrm{L}=$ $\mathrm{BDC}^{2-}$ or $\left.\mathrm{BDC}^{2-} / \mathrm{NO}_{2}-\mathrm{BDC}^{2-}\right)[23]$, with a descending tendency across the series attributed to the lanthanide contraction. The asymmetric units of 2-5 are similar comprising only one unique lanthanide metal ion which exhibits the same nine-fold coordination of the squareface capped square antiprismatic geometry, $S A P R S-\left\{\mathrm{LaO}_{9}\right\}$, as exemplified in Fig. 2. Two modes of coordination including the $\mu_{4}-\eta^{1}: \eta^{1}: \eta^{2}: \eta^{2}$ and $\mu_{4}-\eta^{1}: \eta^{1}: \eta^{1}: \eta^{1}$ are adopted by the ligands upon the coordination leading to the formation of the one-dimensional $\left\{\operatorname{Ln}\left(\mu_{3}-\right.\right.$ $\left.\mathrm{OCO})_{4}\left(\mu_{2}-\mathrm{OCO}\right)_{2}\left(\eta^{1}, \eta^{1}-\mathrm{OCO}\right)\left(\mathrm{OH}_{2}\right)\right\}$ chains extending along the direction of $a$ (Fig. 3a). These chains are further linked by the ligands to form a three-dimensional framework which can be simplified to the four-connected uninodal $\mathbf{N b O}$ net (Fig. 3b). 
The framework includes the one-dimensional rectangular channel extending in the same direction as the $\left\{\mathrm{Eu}\left(\mu_{3}-\mathrm{OCO}\right)_{4}\left(\mu_{2}-\mathrm{OCO}\right)_{2}\left(\eta^{1}, \eta^{1}-\mathrm{OCO}\right)\left(\mathrm{OH}_{2}\right)\right\}$ chains, housing the unbound water molecules. In the same fashion to $\left[\mathrm{Ln}\left(\mathrm{NO}_{2}-\mathrm{BDC}\right)(\mathrm{L})_{0.5}\left(\mathrm{H}_{2} \mathrm{O}\right)\right] \cdot 3 \mathrm{H}_{2} \mathrm{O}[23]$, these unbound water molecules are organized as the edge-shared pentagons by strong hydrogen bonding interactions (Table 2). Besides the hydrogen bonding interactions, there are $\pi-\pi$ interactions between the adjacent organic ligands. The distances and angles between the centroids of the two aromatic rings, range from $4.022 \AA$ and $78.7^{\circ}$ in $2(\mathrm{Eu})$ to $3.951 \AA$ and $78.0^{\circ}$ in 5 (Ho). The effective sizes of the channel openings of 2-5 are similar $\left(4 \times 8 \AA^{2}\right)$ which is also similar to those of $\left[\mathrm{Ln}\left(\mathrm{NO}_{2}-\mathrm{BDC}\right)(\mathrm{L}) 0.5\left(\mathrm{H}_{2} \mathrm{O}\right)\right] \cdot 3 \mathrm{H}_{2} \mathrm{O}[23]$. If the unbound water molecules are excluded, the solvent accessible void volumes of $895.7 \AA^{3}(2 ; 25.87 \%), 848.7$ $\AA^{3}(3 ; 24.88 \%), 825.4 \AA^{3}(4 ; 24.40 \%), 809.0 \AA^{3}(5 ; 24.10 \%)$ could be calculated. The slight decrease of these values across the lanthanide series are in good agreement with the lanthanide contraction.

$\left[\mathbf{T m}\left(\mathrm{NO}_{2}-\mathrm{BDC}\right)_{1.5}\left(\mathrm{H}_{2} \mathrm{O}\right)\right] \cdot \mathrm{H}_{2} \mathrm{O}(\mathbf{6})$. Complex 6 crystallizes in the monoclinic $C 2 / C$ space group comprising only one unique thulium ion which is eight-fold coordinated in a distorted square-face bicapped trigonal prismatic geometry, TPRS-\{TmO8\} (Fig. 4a). Every two TPRS- $\left\{\mathrm{TmO}_{8}\right\}$ motifs are linked by four carboxyl bridges, i.e. $2 \times \mu_{2}-\eta^{1}: \eta^{1}$ $(\mathrm{O} 10-\mathrm{C} 14-\mathrm{O} 10$ and $\mathrm{O} 7-\mathrm{C} 9-\mathrm{O} 7)$ and $2 \times \mu_{2}-\eta^{2}: \eta^{1}(\mathrm{O} 5-\mathrm{C} 8-\mathrm{O} 6)$, to form an edge-shared $\left\{\mathrm{Tm}_{2} \mathrm{O}_{12}\right\}$ dimer (Fig. $4 \mathrm{~b}$ ). These dimers are then connected by the $\mathrm{NO}_{2}-\mathrm{BDC}^{2-}$ ligands through $\mu_{4}-\eta^{1}: \eta^{1}: \eta^{1}: \eta^{1}$ and $\mu_{4}-\eta^{2}: \eta^{1}: \eta^{1}: \eta^{1}$ modes of coordination establishing the threedimensional framework. There are rectangular channels extending along the direction of $b$ of the framework housing the water of crystallization. The crystallizing water molecule is in close proximity to both the coordinating water and the carboxylate oxygen atoms rendering a strong $\mathrm{O}-\mathrm{H} \cdots \mathrm{O}$ hydrogen bonding interactions (Table 2). The framework structure of 6 is further stabilized by the other extensive weak interactions, including the weak $\mathrm{C}-\mathrm{H} \cdots \mathrm{O}$ 
hydrogen bonding and the aromatic $\pi-\pi$ parallel-displaced interactions. The distance and angle between the centroids of the two aromatic rings of two adjacent $\mathrm{NO}_{2}-\mathrm{BDC}^{2-}$ are 3.929 $\AA$ and $82.5^{\circ}$, respectively. The framework of 6 notably contains negligible solvent accessible void. If the edge-shared $\left\{\mathrm{Tm}_{2} \mathrm{O}_{12}\right\}$ dimer is regarded as node with the organic ligand as a linker, the framework of $\mathbf{6}$ can be intriguingly simplified to the same uninodal pcu $\alpha$-Po net as that of 1 (Fig. 4c), although degrees of puckering of the two nets are different. According to the literature, the structure of $\mathbf{6}$ is isostructural to those of the recently reported [ $\mathrm{Ln}_{2}\left(\mathrm{NO}_{2}-\right.$ $\left.\mathrm{BDC})_{3}\left(\mathrm{H}_{2} \mathrm{O}\right)_{2}\right] \cdot 2\left(\mathrm{H}_{2} \mathrm{O}\right)(\mathrm{Ln}=\mathrm{Sm}, \mathrm{Eu}, \mathrm{Gd}, \mathrm{Tb}, \mathrm{Er})$ which were synthesized directly using the $\mathrm{NO}_{2}-\mathrm{H}_{2} \mathrm{BDC}$ ligand under hydrothermal and slow evaporation conditions [28].

Intriguingly, the eight-fold coordination as found for the unoccupied $f$ orbital in lanthanum ion (1) and the smallest thulium ion (6) results in similar dense frameworks with negligible void and the same pcu $\alpha$-Po topology. This is however not the case for $\left[\mathrm{Ln}_{2}\left(\mathrm{NO}_{2}-\right.\right.$ $\left.\mathrm{BDC})_{3}\left(\mathrm{H}_{2} \mathrm{O}\right)_{2}\right] \cdot 2\left(\mathrm{H}_{2} \mathrm{O}\right)(\mathrm{Ln}=\mathrm{Sm}, \mathrm{Eu}, \mathrm{Gd}, \mathrm{Tb}, \mathrm{Er})$, where the $\mathrm{NO}_{2}-\mathrm{H}_{2} \mathrm{BDC}$ was used as the sole linker during the synthesis [28]. This implies the influence of the $\mathrm{NO}_{2}-\mathrm{BDC}^{2-}$ linker in regulating the construction of such a dense framework which may be due to the steric nitro group on the linker, and the crucial role of the $\mathrm{BDC}^{2-}$ linker in providing genuine microporosity to the derived frameworks.

\subsection{Thermal stability and gas sorption behavior of 2}

To investigate gas sorption behavior of the reported microporous complexes, thermal stability of $\mathbf{2}$ (as a representative of $\mathbf{2 - 5}$ ) was investigated by thermogravimetric analysis. It is apparent that the complex remains stable up to over $400{ }^{\circ} \mathrm{C}$ (Fig. 5) despite the two successive losses of both the unbound and the coordinating water molecules (RT- $180{ }^{\circ} \mathrm{C}$; exp. $10.0 \%$, calcd. $10.5 \%$ ). Nonetheless, such losses resulted in the vanishing of the longrange order in the $c$ direction revealed by the disappearance of the $(00 l)$ reflections in the 
PXRD pattern. The importance of the hydrogen bonded water molecules which are organized in the framework void in regulating the framework is therefore illustrated. The persistence of the $h 00$ and $0 k 0$ reflections with appreciable intensities, on the other hand, suggests the retention of the framework crystallinity in the other two directions. A slight shift of the (0 2 0) diffraction peak to lower $2 \theta$ for the heat-treated samples implies the modest alteration of the framework structure after the losses of the water molecules. Stability of the framework and the retention of the framework microporosity after the removal of the water molecules were confirmed by the classical type I sorption isotherm of the nitrogen gas collected at $77 \mathrm{~K}$ (Fig. 6a). The surface area of $543 \mathrm{~m}^{2} \cdot \mathrm{g}^{-1}$ could be calculated based on the BET model with an average pore size of $1.2 \mathrm{~nm}$.

The sample exhibited similar adsorption behavior for carbon dioxide gas (Fig. 6b). The sudden uptake of the gas signifies the interactions of the gas molecule with the unoccupied coordination sites on the europium ions generated by the removal of the coordinated water. The maximum gravimetric capacity of approximately $19 \mathrm{wt} \%$, which is equivalent to $95 \mathrm{~cm}^{3} \cdot \mathrm{g}^{-1}$ or $4.2 \mathrm{mmol} \cdot \mathrm{g}^{-1}$, was achieved at extremely low pressure of less than $10 \mathrm{kPa}$ or 0.1 bar. This value is much higher than those reported for zeolitic materials [3], and comparable to some recently reported MOFs under similar measuring temperatures and pressures such as $\left[\left(\mathrm{Ni}_{2} \mathrm{~L}^{2}\right)(\mathrm{bptc})\right] \cdot 6 \mathrm{H}_{2} \mathrm{O} \cdot 3 \mathrm{DEF},\left[\left(\mathrm{Ni}_{2} \mathrm{~L}^{4}\right)(\mathrm{bptc})\right] \cdot 14 \mathrm{H}_{2} \mathrm{O}\left(\mathrm{bptc}^{4-}=1,1^{\prime}-\right.$ biphenyl$3,3^{\prime}, 5,5^{\prime}$-tetracarboxylate, $\mathrm{DEF}=N, N$-diethylformamide) [29], and $\left[\mathrm{Co} 2.5(\mathrm{btc})(\mathrm{Hbtc})_{0.5}(\mathrm{atz})\left(\mathrm{CH}_{3} \mathrm{CN}\right)\left(\mathrm{H}_{2} \mathrm{O}\right)\right] \cdot \mathrm{H}_{2} \mathrm{O}\left(\mathrm{H}_{3} \mathrm{btc}=1,3,5\right.$-benzenetricarboxylic acid, atz $=$ 3-amino-1,2,4-triazole) [30]. In addition to the interactions to the exposed europium ions, the interactions between the polar nitro groups on the $\mathrm{NO}_{2}-\mathrm{BDC}^{2-}$ linker and the carbon dioxide molecule [30-32] should also contribute to the significant uptake capacity in $\mathbf{2}$. Intriguingly, this capacity was retained even after six cycles of sorption/desorption experiments with the intact framework crystallinity revealed by both the powder (Fig. 5) and single crystal X-ray 
diffraction experiments. A single crystal that had been used for six cycles of gas sorption was exposed to air for a period of a few weeks and then examined by single crystal X-ray diffraction. This demonstrated that the same network present in the pristine sample is retained. The structure refinement of this crystal (data to $56.5^{\circ} 2 \theta$ for Mo radiation) converged with $R=4.53 \%$ and $\mathrm{w} R\left(F^{2}\right)=7.13 \%$. The stability of the framework and therefore recyclability of the material is one of the most desired properties for the storage applications [33].

Rather than an abrupt increase in gravimetric adsorption like that observed for the nitrogen and carbon dioxide gases, the uptake of the hydrogen gas by $\mathbf{2}$ gradually occurred over a range of pressures before reaching approximately $0.80 \mathrm{wt} \%$ at $1 \mathrm{bar}$, which is equivalent to $79 \mathrm{~cm}^{3} \cdot \mathrm{g}^{-1}$ or $4 \mathrm{mmol} \cdot \mathrm{g}^{-1}$ (Fig. 6c). This gravimetric sorption capacity is comparable to those reported for the best zeolite ZSM-5 [34] and the series of Co-INA, COFINA and IRMOF [35]. The rather small gravimetric capacities observed for 2 attributes partially to relatively heavy framework compared to the light weight of the hydrogen gas. The gradual increase in the sorption with increasing pressure at low temperatures is notably characteristic of the physisorption process in the microporous solids [36], which is reported to be potential for the pressure swing adsorption processes [37]. Regarding the structure of $\mathbf{2}$, the sorption of the hydrogen gas should occur through the interactions with the electron rich phenyl rings of both the $\mathrm{BDC}^{2-}$ and $\mathrm{NO}_{2}-\mathrm{BDC}^{2-}$ linkers [38].

\subsection{Photoluminescence properties of 1-6}

The $\mathrm{NO}_{2}-\mathrm{BDC}^{2-}$ ligand has been reported previously as a poor sensitizer in $\left[\mathrm{Ln}\left(\mathrm{NO}_{2}-\right.\right.$ $\left.\mathrm{BDC})(\mathrm{L})_{0.5}\left(\mathrm{H}_{2} \mathrm{O}\right)\right] \cdot 3 \mathrm{H}_{2} \mathrm{O}[23]$ and the closely relevant $\left[\mathrm{Ln}_{2}(\mathrm{NTA})_{3}\left(\mathrm{OH}_{2}\right)_{2}\right]\left(\mathrm{H}_{2} \mathrm{O}\right)_{2}(\mathrm{Ln}=\mathrm{Sm}$, $\mathrm{Eu}, \mathrm{Gd}, \mathrm{Tb}, \mathrm{Er}$ and $\mathrm{H}_{2} \mathrm{NTA}=$ 2-nitroterephthalic acid) [28], which is also true for the complexes reported here. Upon the excitation at $255 \mathrm{~nm}$, similar broad bands covering almost 
the entire region of the visible light derived from the intra-ligand charge transfer (ILCT) transitions is present, as exemplified in Fig. 7. Characteristic emissions of the europium (2; $\left.{ }^{5} \mathrm{D}_{0} \rightarrow{ }^{7} \mathrm{FJ}_{\mathrm{J}} \mathrm{J}=1,2,3,4\right)$ and terbium $\left(3 ;{ }^{5} \mathrm{D}_{4} \rightarrow{ }^{7} \mathrm{FJ}_{\mathrm{J}} \mathrm{J}=3,4,5,6\right)$ can, nonetheless, be observed. These emission bands are significantly less intense relative to other europium and terbium complexes which agree with the poor sensitizing role of the $\mathrm{NO}_{2}-\mathrm{BDC}^{2-}$ ligand. The relatively high intensity of the ${ }^{5} \mathrm{D}_{0} \rightarrow{ }^{7} \mathrm{~F}_{2}$ band in the spectrum of complex 2 can be attributed to the absence of the inversion center at the europium ion crystallographic site [28].

\section{Conclusions}

By employing the $\mathrm{H}_{2} \mathrm{BDC}$ ligand and the in situ nitration reaction, six new lanthanide metal organic complexes have been synthesized; $\left[\mathrm{La}_{2}\left(\mathrm{NO}_{2}-\mathrm{BDC}\right)_{3}\left(\mathrm{H}_{2} \mathrm{O}\right)_{4}\right]$ (1) $\left[\mathrm{Ln}(\mathrm{L})_{0.5}\left(\mathrm{NO}_{2}-\right.\right.$ $\left.\mathrm{BDC})\left(\mathrm{H}_{2} \mathrm{O}\right)\right] 3 \mathrm{H}_{2} \mathrm{O}\left(\mathrm{Ln}=\mathrm{Eu}(\mathbf{2}), \mathrm{Tb}(\mathbf{3})\right.$, $\mathrm{Dy}(\mathbf{4})$ and $\mathrm{Ho}(\mathbf{5}) ; \mathrm{L}=\mathrm{BDC}^{2-}$ or $\left.\mathrm{BDC}^{2-} / \mathrm{NO}_{2}-\mathrm{BDC}^{2-}\right)$ and $\left[\mathrm{Tm}\left(\mathrm{NO}_{2}-\mathrm{BDC}\right){ }_{1.5}\left(\mathrm{H}_{2} \mathrm{O}\right)\right] \cdot \mathrm{H}_{2} \mathrm{O}(\mathbf{6})$. Complexes $\mathbf{1}$ and $\mathbf{6}$ are can be simplified to the same topology of pcu $\alpha$-Po net despite the different framework structures, and the isostructural frameworks of 2-5 can be simplified to the $\mathbf{N b O}$ net. Whilst the frameworks of $\mathbf{1}$ and $\mathbf{6}$ contained negligible void, those of 2-5 are microporous in nature with similar void opening of $4 \times 8 \AA^{2}$ and solvent accessible void volumes varying in a range of 809.0-895.7 $\AA^{3}$.

Complex 2 (as a representative of 2-5) exhibits exceptional stability upon the loss of all the water in the structure and also the heat treatment. After the loss of the water, the BET surface area of $543 \mathrm{~m}^{2} \cdot \mathrm{g}^{-1}$ and an average pore size of $1.2 \mathrm{~nm}$ can be calculated for $\mathbf{2}$, which shows significant adsorption capacities for both carbon dioxide $\left(95 \mathrm{~cm}^{3} \cdot \mathrm{g}^{-1}\right.$ or $\left.4.2 \mathrm{mmol} \cdot \mathrm{g}^{-1}\right)$ and hydrogen gases $\left(79 \mathrm{~cm}^{3} \cdot \mathrm{g}^{-1}\right.$ or $\left.4 \mathrm{mmol} \cdot \mathrm{g}^{-1}\right)$. The framework shows high stability even after six cycles of sorption/desorption experiments. The poor sensitizing ability of the $\mathrm{NO}_{2}-\mathrm{BDC}^{2-}$ ligand has been illustrated. 


\section{Appendix A. Supplementary data}

The IR spectra assignments and illustrations of different coordination modes observed in the title complexes as well as the three-dimensional framework of $\mathbf{2}$ after six cycles of carbon dioxide sorption/desorption experiments can be found as supplementary data. Crystallographic data for the title complexes have been deposited with the Cambridge Crystallographic Data Centre; CCDC 1517766-1517771. Copies of this information may be obtained free of charge from The Director, CCDC, 12 Union Road, Cambridge CB2 1EZ, UK (fax: +44 1223 336033; e-mail: deposit@ccdc.cam.ac.uk).

\section{Acknowledgements}

The work is co-funded by the Thailand Research Fund (RSA5980026) and Chiang Mai University. K. Panyarat thanks to the Science Achievement Scholarship of Thailand for the Ph.D. scholarships.

\section{References}

[1] H. Yang, Z. Xu, M. Fan, R. Gupta, R.B. Slimane, A.E. Bland, I. Wright, J. Environ. Sci. 20 (2008) 14-27.

[2] J.D. Figueroa, T. Fout, S. Plasynski, H. McIlvried, R.D. Srivastava, Inter. J. Greenh. Gas Control. 2 (2008) 9-20.

[3] R. Sabouni, H. Kazemian, S. Rohani, Environ. Sci. Pollut. Res. 21 (2014) 5427-5449.

[4] K. Sumida, D.L. Rogow, J.A. Mason, T.M. McDonald, E.D. Bloch, Z.R. Herm, T.-H. Bae, J.R. Long, Chem. Rev. 112 (2012) 724-781.

[5] M.T. Ho, G.W. Allinson, D.E. Wiley, Ind. Eng. Chem. Res. 47(14) (2008) 4883-4890.

[6] M. Eddaoudi, D.B. Moler, H. Li, B. Chen, T.M. Reineke, M. O’Keeffe, O.M. Yaghi, Acc. Chem. Res. 34(4) (2001) 319-330. 
[7] R.J. Kuppler, D.J. Timmons, Q.-R. Fang, J.-R. Li, T.A. Makal, M.D. Young, D. Yuan, D. Zhao, W. Zhuang, H.-C. Zhou, Coord. Chem. Rev. 253 (2009) 3042-3066.

[8] M.J. Rosseinsky, Micropor. Mesopor. Mater. 73 (2004) 15-30.

[9] H. Li, M. Eddaoudi, T.L. Groy, O.M. Yaghi, J. Am. Chem. Soc. 120(33) (1998) 85718572.

[10] J. Liu, P.K. Thallapally, B.P. McGrail, D.R. Brown, J. Liu, Chem. Soc. Rev. 41 (2012) $2308-2322$.

[11] D. Andirova, C.F. Cogswell, Y. Lei, S. Choi, Micropor. Mesopor. Mater. 219 (2016) 276-305.

[12] T.M. Reineke, M. Eddaoudi, M. Fehr, D. Kelley, O.M. Yaghi, J. Am. Chem. Soc. 121(8) (1999) 1651-1657.

[13] T.M. Reineke, M. Eddaoudi, M. O’Keeffe, O.M. Yaghi, Angew. Chem. Int. Ed. 38(17) (1999) 2590-2593.

[14] Z.-J. Lin, Z. Yang, T.-F. Liu, Y.-B. Huang, R. Cao, Inorg. Chem. 51 (2012) 1813-1820.

[15] M. Eddaoudi, H. Li, T. Reineke, M. Fehr, D. Kelley, T.L. Groy, O.M. Yaghi, Top. Catal. 9 (1999) 105-111.

[16] D.K. Maity, A. Halder, B. Bhattacharya, A. Das, D. Ghoshal, Cryst. Growth Des. 16 (2016) 1162-1167.

[17] Bruker, SAINT, Bruker AXS Inc., Madison, Wisconsin, USA, 2007.

[18] L. Krause, R. Herbst-Irmer, G.M. Sheldrick, D. Stalke, J. Appl. Crystallogr. 48 (2015) 310.

[19] J. de Meulenaer, H. Tompa, Acta Crystallogr. 19 (1965) 1014.

[20] G.M. Sheldrick, Acta Crystallogr. A64 112 (2008) 112-122.

[21] L.J. Farrugia, J. Appl. Crystallogr. 32 (1999) 837-838. 
[22] O.V. Dolomanov, L.J. Bourhis, R.J. Gildea, J.A.K. Howard, H. Puschmann, J. Appl. Crystallogr. 42 (2009) 339-341.

[23] K. Panyarat, T.J. Prior, A. Rujiwatra, Polyhedron 81 (2014) 74-80.

[24] H.-P. Xiao, L.-G. Zhu, Inorg. Chem. Commun. 9 (2006) 1125-1128.

[25] N.J. Tapp, D.M. Bibby, N.M. Milestone, Zeolites, 8 (1988) 157-159.

[26] Z.-S. Yao, K. Yamamoto, H.-L. Cai, K. Takahashi, O. Sato, J. Am. Chem. Soc., 138 (37) (2016) $12005-12008$.

[27] A.L. Spek (1980-2014). PLATON. Version 191114. Utrecht University, Padualaan 8, 3584 CH Utrecht, The Netherlands.

[28] J.A. Smith, M.A.S. Wilmot, K.P. Carter, C.L. Cahill, A.J. Loughc, C.S. Knee, New J. Chem. 40 (2016) 7338-7349.

[29] H.-S. Choi, M.P. Suh, Angew. Chem. Int. Ed. 48 (2009) 6865-6869.

[30] B. Liu, R. Zhao, K. Yue, J. Shi, Y. Yu, Y. Wang, Dalton Trans. 42 (2013) 13990-13996.

[31] Z. Zhang, Z.-Z. Yao, S. Xiang, B. Chen, Energy Environ. Sci. 7 (2014) 2868-2899.

[32] M.T. Kapelewski, S.J. Geier, M.R. Hudson, D. Stück, J.A. Mason, J.N. Nelson, D.J. Xiao, Z. Hulvey, E. Gilmour, S.A. FitzGerald, M.H. Gordon, C.M. Brown, J.R. Long, J. Am. Chem. Soc. 136 (2014) 12119-12129.

[33] H. Furukawa, K.E. Cordova, M. O’Keeffe, O.M. Yaghi, Science 341 (2013) 1230444.

[34] A. Phan, C. Doonan, F.J.U. Romo, C.B. Knobler, M. O’Keeffe, O.M. Yaghi, Acc. Chem. Res. 43(9) (2010) 58-67.

[35] P. Pachfule, Y. Chen, J. Jiang, R. Banerjee, Chem. Eur. J. 18 (2012) 688-694.

[36] M. Thommes, K. Kaneko, A.V. Neimark, J.P. Olivier, F.R. Reinoso, J. Rouquerol, K.S.W. Sing, Pure Appl. Chem. 87 (2015) 1051-1069.

[37] B. Silva, I. Solomon, A.M. Ribeiro, U.H. Lee, Y.K, Hwang, J.-S. Chang, J.M. Loureiro, A.E. Rodrigues, Sep. Purif. Technol. 118 (2013) 744-756. 
[38] D.J. Collins, H.-C. Zhou, J. Mater. Chem. 17 (2007) 3154-3160. 


\section{Figure captions}

Fig. 1 Views of (a) an extended asymmetric unit drawn as 50\% thermal ellipsoids, (b) the three-dimensional framework, and (c) the simplified pcu $\alpha$-Po topology of $\mathbf{1}$.

Symmetry operations: (i) $2-x,-1-y, 1-z$ (ii) $2-x,-y, 1-z$ (iii) $x,-1+y, z$ (iv) $x, 1+y, z$ (v) $1-x, 1-y, 1-z$ (vi) $2-x,-y, 1-z$ (vii) $1-x,-y, 1-z$ (viii) $1-x, 2-y, 2-z$ (ix) 2-x, -1-y, -z (x) $x$, $y, 1+z$.

Fig. 2 Views of the extended asymmetric units of (a) 2 and (b) 4 both of which are drawn as $50 \%$ thermal ellipsoids. Symmetry operations for 2 : (i) $0.5+x, 0.5-y, 1-z$ (ii) $x$, $0.5-y, 0.5+z$ (iii) $0.5+x, y, 0.5-z$ (iv) $1-x,-y, 1-z$. For 3: (i) $1.5-x, 1-y,-0.5+z$ (ii) $1.5-x$, $0.5+y, z$ (iii) $x, 0.5-y,-0.5+z$ (iv) $1.5-x, 1-y, 0.5+z$ (v) $x, 0.5-y, 0.5+z$ (vi) $1-x, 1-y, 2-z$.

Fig. 3 Illustrations showing (a) the three-dimensional framework and (b) the simplified NbO topology of $\mathbf{2}$ (as a representative of 2-5).

Fig. 4 Views of (a) an extended asymmetric unit drawn as 50\% thermal ellipsoids, (b) a dense three-dimensional framework, and (c) the simplified pcu $\alpha$-Po topology of $\mathbf{6}$. Symmetry operations: (i) $0.5+x, 1.5-y, 0.5+z$ (ii) $1.5-x, 0.5+y, 1.5-z$ (iii) $2-x, y, 1.5-z$ (iv) $x, 1+y, z$.

Fig. 5 The PXRD pattern of the pristine sample of 2 compared with the pattern simulated from single crystal data and those of the treated samples with the enlargement of the low $2 \theta$ area and the thermogravimetric curve in the insets.

Fig. 6 Gas sorption/desorption isotherms of (a) nitrogen (b) carbon dioxide and (c) hydrogen gases.

Fig. 7 Photoluminescence spectra (solid lines) of (a) 1 (as a representative of $\mathbf{1}$ and 4-6) (b) 2, and (c) 3, compared with those of the $\mathrm{H}_{2} \mathrm{BDC}$ (dotted lines). 